\title{
Development of Enterprise Architecture Model for Smart City
}

\author{
Saluky \\ Department of Electrical Engineering and Informatics \\ Bandung Institute of Technology \\ Bandung \\ luke4line@gmail.com
}

\begin{abstract}
Population development is so fast and half within the city that it creates social problems. In addition, the city also has future challenges such as population growth, poverty, health, safety, energy needs, and pollution levels. The problems and challenges of the city must get the solution through the use of the smart city concept in managing the city. Smart City is a city with a development concept using existing resources effectively and efficiently and can be used to maximize the benefits of citizens through the use of information and communication technology. To build a smart city It takes enterprise architecture as a medium of communication by all the intelligent city stakeholders that can be achieved in accordance with predetermined goals. This research aims to develop the enterprise architecture model by using TOGAF to be used and provide solutions to the problems and challenges of the city through the development of enterprise smart city architecture. The results show that Smart City Enterprise Architecture developed using TOGAF can be used as a reference for smart city development.
\end{abstract}

Keywords - Smart City, Architecture Enterprise, TOGAF

\section{INTRODUCTION}

The development of information technology today brings a very significant change. Humans create technology with motivation and encouragement to make life better [1]. One of the factors driving organizations to take advantage of enterprise architecture is that the organization's growing need for business functions and business processes is being carried out when organizations want to plan the development of enterprise architecture that suits their needs will be difficult due to the number of methodologies or frameworks that can be used. The selection of appropriate methodologies will provide a clear picture of the enterprise architecture to be built. In addition to these issues in today's organizations are also faced with how to align business strategy with technology strategy, to address this challenge organization must develop enterprise architecture that must be able to provide a framework for making informed long-term information technology decisions taking into account organizational needs overall. In principle, enterprise architecture is a tool used to realize the alignment of information technology with the business run organization.

Such alignment can only be achieved if the organization truly defines its needs thoroughly, starting from defining the business architecture of the organization, the data architecture to be used, the architect of the application to be built and the technology architecture which will support the application. Every process and stage in developing enterprise architecture are very concerned about the existing business domains within the organization, while the data or information and technology domains are strongly influenced by the development of technology and applications. The role of business domains in the development of enterprise architecture will affect other domains. False in defining the existing business needs, it will be wrong in the implementation stage [2].

Along with the development of technology is changing also the order of community life and city life becomes a major challenge in our daily lives.

In 2007, 50\% of the world's population lives in cities. The UN Population Data estimates that by 2030 about $60 \%$ of the world's population will live in urban environments[3]. Implementation of a smart city in several cities in Indonesia turned out to have various weaknesses and advantages[4]. It needs to be studied further considering the big cities in Indonesia certainly have many similarities, but apparently, the application of the concept of Smart City in each big city has a different background[1]. In this research will do development of enterprise architecture model smart city with a case study in Cirebon City. 
Research Problems

Based on the background that has been discussed before the following problems as follows:

- How can Smart City be achieved through good planning and availability of communication media between stakeholders and participation by using architectural firms such as TOGAF?

- How can smart city be applied to a city by looking at all the potential owned by the region or city so that its implementation can run smoothly and success?

Related Works

There are a number of scientific works related to smart city research such as about designing Enterprise Architecture smart city case study of Bandung city[5], Internet application architecture for future smart city[6], smart city concept for tourism in Malang city[7], and comparison of smart city Cities in Europe are analyzed through the smart city web portal. In this study takes a gap that has not been discussed in previous studies.

\section{LITERATURE REVIEW}

\section{A. Smart City}

Definition or understanding Smart City is very diverse. The concept has been popularly known, but in practice, it is used in different countries with different terms and different situations[5]. There is the use of different types of smart replacing concepts with other adjectives. Smart City is defined as a city that monitors conditions and integrates infrastructure, which includes roads, bridges, tunnels, railways, underground streets, airports, seaports, communications, water, electricity and even buildings, allowing optimal resources through maintenance planning Preventive and security monitoring conditions in order to maximize service to its citizens [8]. Another smart city definition states Smart City as a city connecting physical infrastructure, IT infrastructure, social infrastructure, and business infrastructure utilizing city-owned data intelligence collections[9].

There are at least three criteria that measure the success of a city in an effort to realize the smart city, namely economic aspects, social aspects and environmental aspects. In terms of economy, a smart city is a city that is able to explore and maximize all resources and local potentials that are owned for the maximum utilization of the welfare of the community. From a social point of view, a smart city is a city that is able to provide security, comfort and easy access for every element of society in interacting. In terms of the environment, a smart city is a city that is able to provide space (public or personal) is healthy and livable, and energy efficient.
According to Boyd Cohen split the smart city into 6 main indicators, namely; Smart economy, smart infrastructure, smart environment, smart people, smart living and smart governance.

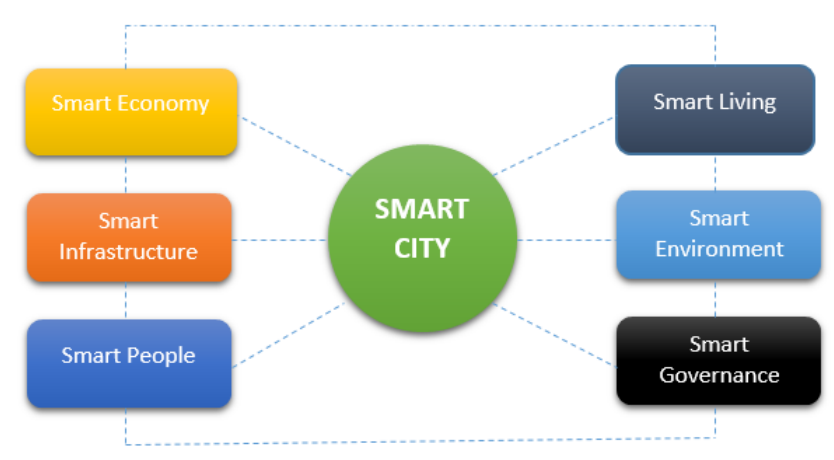

Figure 1: Smart City Components

\section{B. Enterprise Architecture}

Enterprise architecture or better known as enterprise architecture is a description of a stakeholder mission that includes information, functionality/usability, organizational location and performance parameters. The enterprise architecture describes plans to develop a system or set of systems. The main uses of enterprise architecture are to inform, guide, and limit decisions for organizations, especially in making information technology investments. Enterprise architecture can also be used as a way to improve the efficiency of information technology when business innovation is developed. How the implementation of enterprise architecture can be used by the organization, the organization should adopt a method or framework that can be used in the development of enterprise architecture. So that with existing enterprise architecture method is expected to manage complex systems and can align business and information technology to be invested.

Various methodologies can be used in developing an enterprise architecture, including Enterprise Architecture Planning, TOGAF Architecture Development Method, Enterprise Architecture Strategy, Federal Enterprise Architectures and many others. From some of these methodologies there are a common point of view that an enterprise architecture is divided into 4 (four) components, namely:

a) Business Architecture: is seen as a foundation or driver for other components of enterprise architecture. Business Architecture can act as a motivator in developing business plans, technology, application usage and implementation.

b) Data / Information Architecture: viewed as information/data that is used as an asset in business support and later used to determine the needs of the application system, which will be used to manage a set of data entities or manage information. 
c) Application Architecture: is seen as defining the main types of applications that will be used in managing the data that has been collected and required also in business support.

d) Technology Architecture: is seen as the definition of a technology platform that will be used for the provision of application environments in managing data and as a tool in business support. The relationship of organizational components to architectural domains can be defined as hierarchy or level

e) Of the architecture to be developed within an organization. Each level has the same roles and responsibilities to achieve an enterprise architecture that aligns management needs with developed information systems.

\section{TOGAF (The Open Group Architecture Framework)}

Open Group is a neutral consortium of vendors and technology and aims to create global open standards and interoperability to enable access to integrated information within and between companies. TOGAF is an industry standard architecture framework to develop an information system architecture within a company that uses the development method of TOGAF architecture $(\mathrm{ADM})$. It is a framework for enterprise architecture that provides a comprehensive approach for designing, planning, implementing and controlling with authority on an enterprise architecture information. TOGAF is used to develop Enterprise Architecture, where there are detailed methods and tools to implement it, this is what distinguishes it with other EA Framework (Enterprise Architecture) such as Zachman Framework. One of the advantages of using this TOGAF Framework is because it is flexible and open source.TOGAF provides a detailed method of how to build and manage and implement enterprise architecture and information systems called Architecture Development Method $(\mathrm{ADM}) . \mathrm{ADM}$ is a generic method that contains a set of activities used in modeling the development of enterprise architecture. This method can also be used as a guide or tool for planning, designing, developing and implementing information systems architecture for organizations[2].

TOGAF ADM is also a flexible method that can anticipate a variety of modeling techniques used in the design, because this method can be adjusted with changes and needs during the design is done. TOGAF ADM also states a clear vision and principles of how to undertake enterprise architecture development, the principle being used as a measure in assessing the success of enterprise architecture development by organizations. These principles can be explained as follows:

a) Enterprise Principles The development of the architecture is expected to support all parts of the organization, including the organizational units in need.

b) Information Technology Principles More directs consistency of the use of Information Technology in all parts of the organization, including the organizational units that will use.

c) Architectural Principles Designing system architecture based on the needs of business processes and how to implement them.

The first step to consider when implementing TOGAF ADM is to define preparations by identifying the architecture context to be developed, secondly defining the strategy of the architecture and defining the architectural parts to be designed, ie from business architecture, information system architecture, Architecture of the technology, and establish the capabilities of the architecture to be designed and developed The Open Group Architecture Framework (TOGAF) Here's a description of the stages of TOGAF ADM.

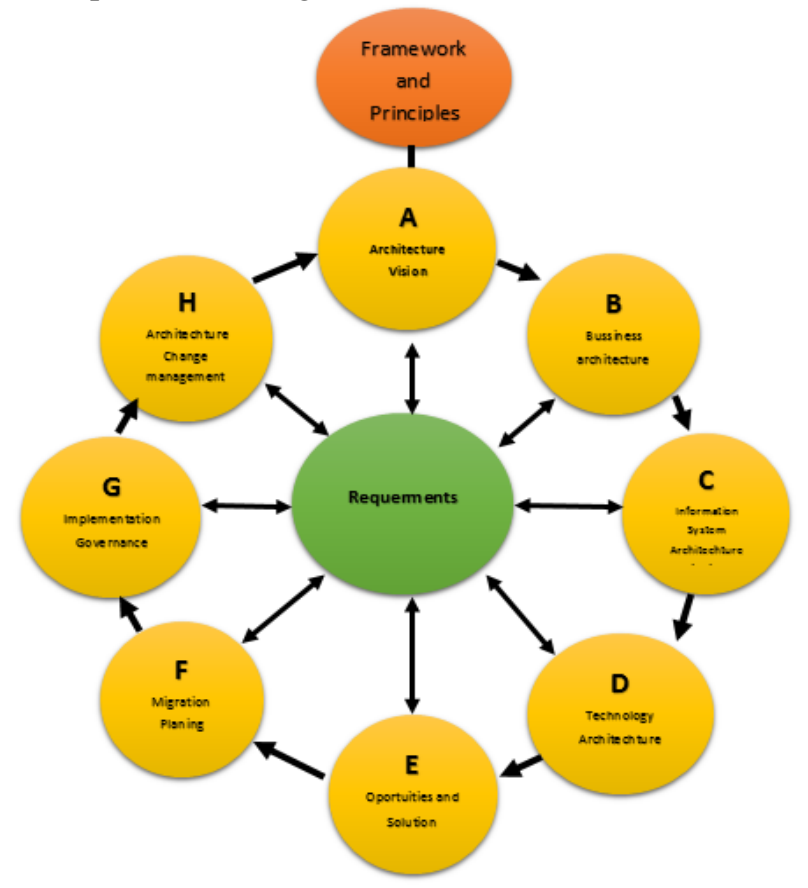

Figure 2: Phase of Architectural development method

Togaf is a holistic approach to design, which is usually modeled on 4 levels: business, applications, data, and technology. It provides an overall feasibility as an early model used as an information architect, which can be built later. It is modularized, standardized and available, technological and 
product improvements. The steps of TOGAF ADM can be summarized as follows:

a) Architecture Vision: Creating uniformity of views on the importance of enterprise architecture to achieve organizational goals formulated in the form of strategy and determine the scope of the architecture to be developed. At this stage, the questions are asked to get the ideal architecture.

b) Business Architecture: Defines the initial state of business architecture, determines the business model or desired business activity based on business scenarios. At this stage tools and common methods for modeling such as BPMN (Business Processing Modeling Notation), IDEF (Integration Definition Function) and UML (Unified Modeling Language) can be used to build the required model.

c) Information System Architecture: At this stage more emphasis on the activity of how the information system architecture developed. The definition of information systems architecture in this stage includes the data architecture and application architecture that will be used by the organization. Data architectures focus more on how data is used for the needs of business functions, processes, and services. In the application architecture is more emphasis on how the application needs are planned by using Application Portfolio Catalog, as well as emphasize on the application model that will be designed. Techniques that can be used include Application Communication Diagram, Application and User Location Diagram and others.

d) Technology Architecture: Build the desired technology architecture, starting from determining the type of technology candidate required by using Technology Portfolio Catalog which includes software and hardware. In this stage also consider the alternatives required in the selection of technology. The techniques used include the Environment and Location Diagrams, Network Computing Diagrams, and others.

e) Opportunities and Solutions: At this stage more emphasis on the benefits derived from enterprise architecture that includes business architecture, data architecture, application architecture, and technology architecture, so that the basis for stakeholders to choose and determine the architecture to be implemented. To model, this stage in the design can use the technique of Project Context Diagram and Benefit Diagram. f) Migration Planning: At this stage will be an assessment in determining the migration plan of an information system. It is usually at this stage for its modeling using a judgment and decision matrix of the main needs and support of the organization towards the implementation of information systems.

g) Implementation Governance Prepares recommendations for implementation of governance implementation that has been done, the governance that is done include Organizational governance, information technology governance, and governance architecture[10].

\section{DISCUSSION}

The initial design of the development of enterprise architecture begins by preparing the needs in accordance with the vision and mission of Cirebon city.

The vision of Cirebon city is the realization of Cirebon City.

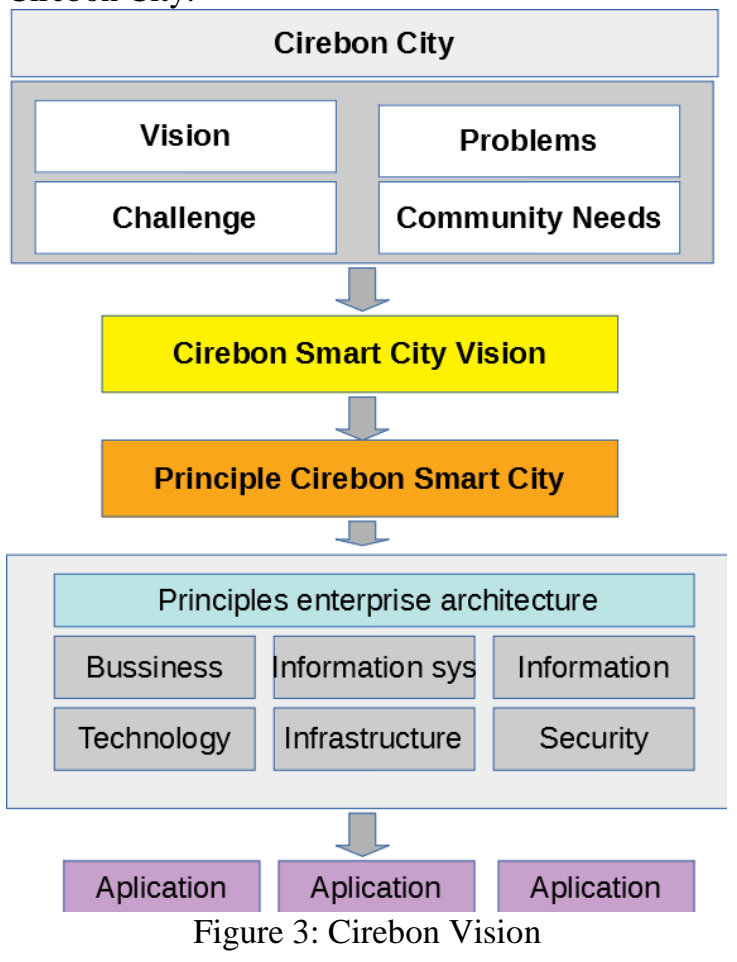

From Figure 4 will be obtained architecture and information technology framework as follows 


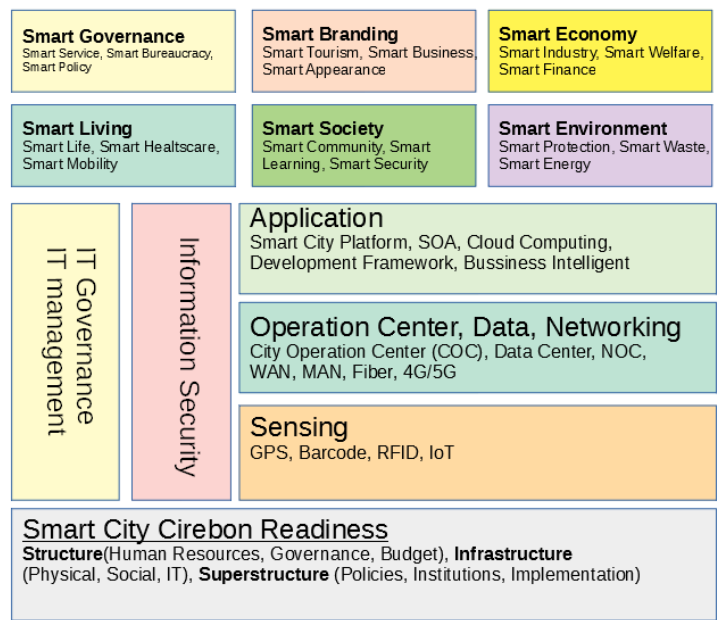

Figure 4: Framework Architechture

From the preparation of the architecture with TOGAF ADM, then obtained the following results:

1. Cirebon Smart City Vision

Smart City's vision is developed based on Cirebon's vision, issues, challenges and resources as liveable, eficient, sustainable, safe.

\section{Smart City Value Chain}

This analysis provides a framework for the identification and inventory of business functions, by grouping functional areas into key activities and support activities. Smart City's value chain starts at the point where data about citizens and the urban environment is generated. The data is then analyzed, combined with other services and delivered via useful and targeted applications and interfaces to the end consumer. Providers have the opportunity to take different roles in different parts of the value chain from pure access to full-service delivery. Here's a picture Smart City Value Chain[11].

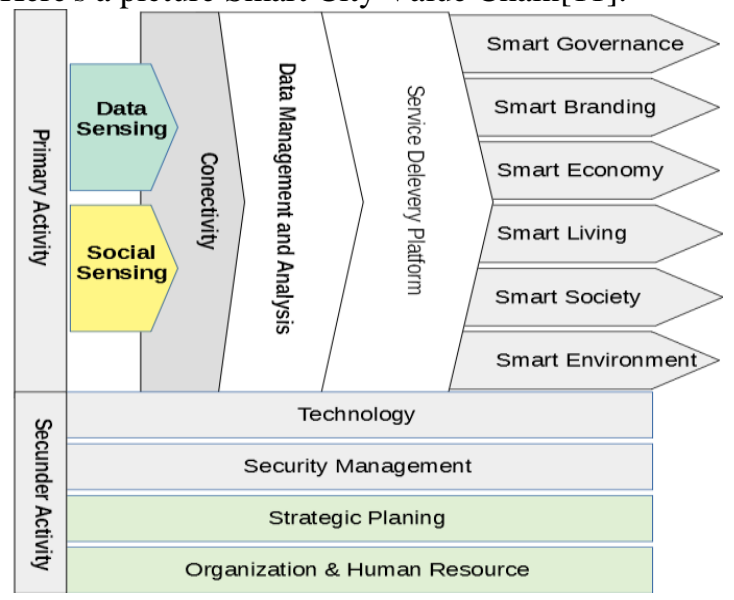

Figure 5: Smart city value chain

From the architecture preparation with TOGAF $\mathrm{ADM}$, the following results are obtained:

1. The concept of smart city solutions

For the development of Cirebon, the smart city must first understand the current conditions so that it can be mapped needs that will come tailored to the vision of the city of Cirebon.

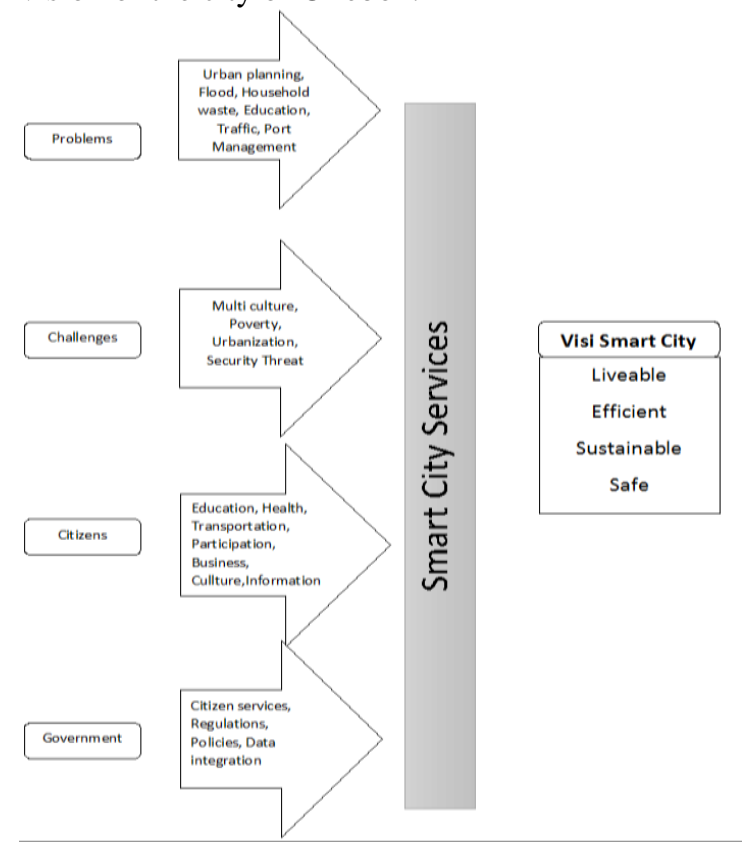

Figure 6: Concepts and Solutions

Figure 5 shows the need for smart city service development based on the issues, challenges, expectations, and needs of citizens, as well as the city government plan as follows:

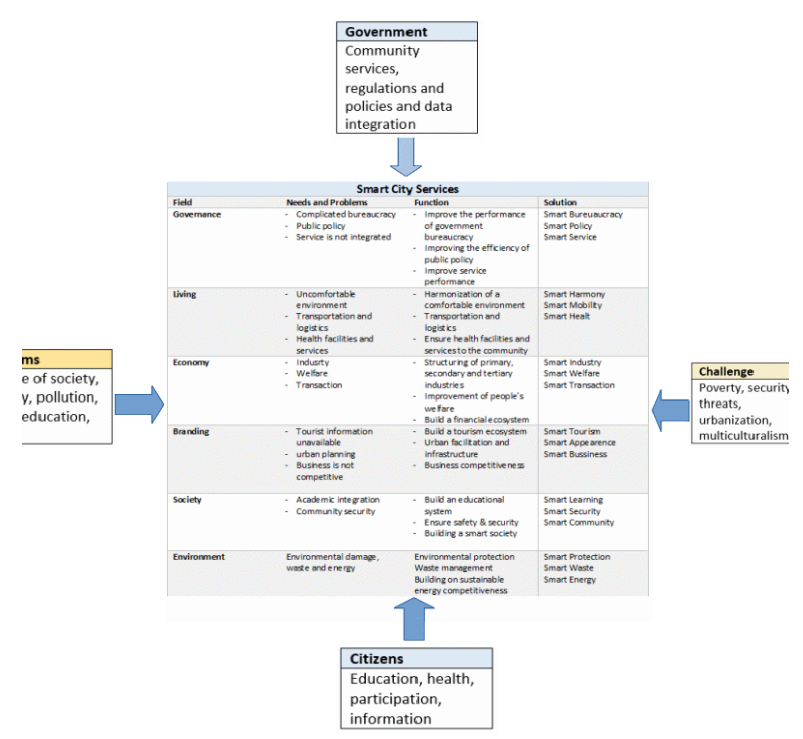

Figure 7: Smart City Cirebon Service

\section{Principle of architecture}

The architectural principles used in accordance with the vision and mission of the city of Cirebon, making it easier to make decisions and solutions in accordance with the enterprise architecture created. Here's an overview of architectural principles 


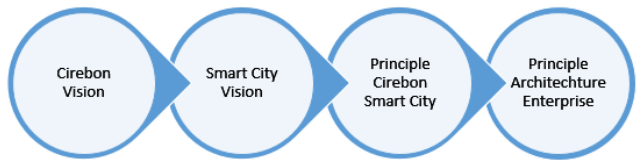

Figure 8: Principle Smart City

3. Architecture Enterprise Principles

Principles of Enterprise Architecture Cirebon city consists of business principles, information, application of principles, principles of technology, infrastructure, and principles.

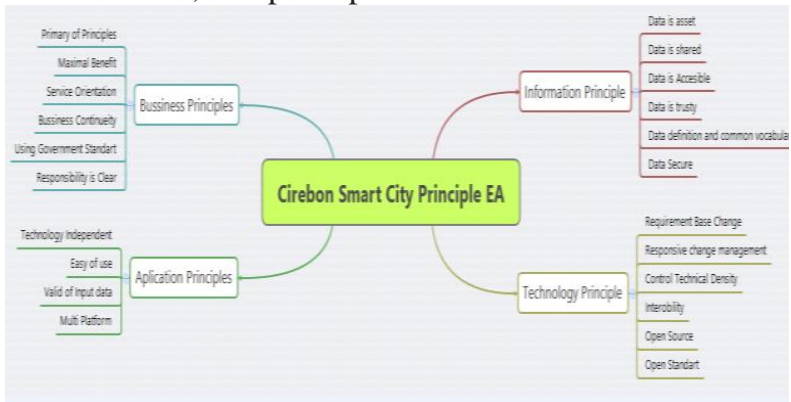

Figure 9: Principles Cirebon Smart City

4. Enterprise Architecture Cirebon

Smart City Enterprise Architecture Cirebon that has been structured as follows:

a. Bussines Architecture

Business architecture is created by combining all data and integrated so there is no redundancy and more effective and efficient that can support the needs of smart city.

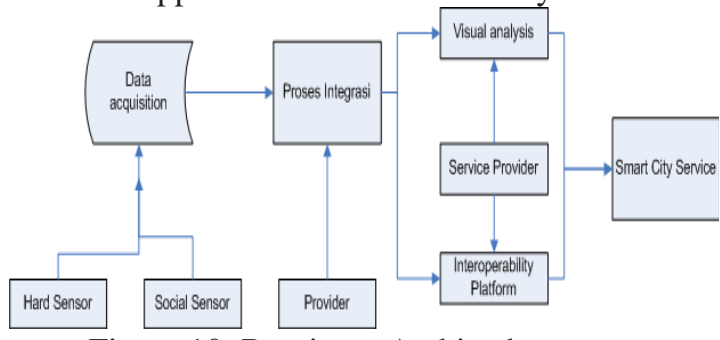

Figure 10: Bussiness Architechture

b. Information System Architechture

Data obtained from the merging were analyzed and made predictions for action in the city of Cirebon

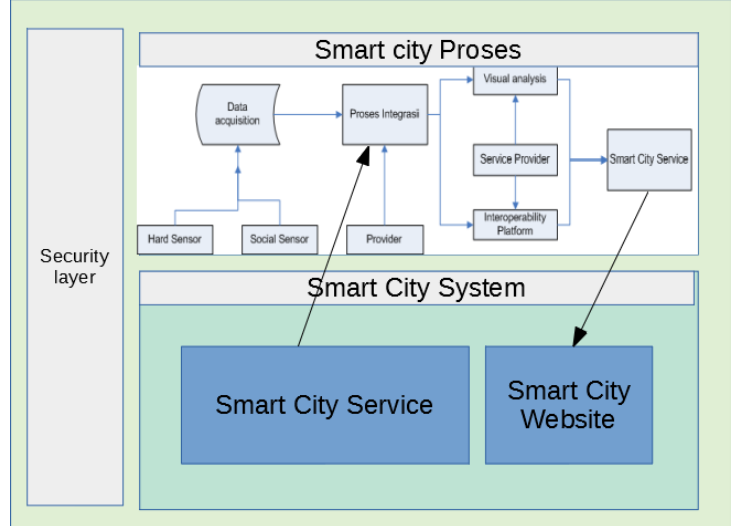

Figure 11: Information Architecture

c. Enterprise Arcitechture

All high-level description results are integrated with components within the city that include business processes, information systems, and infrastructure

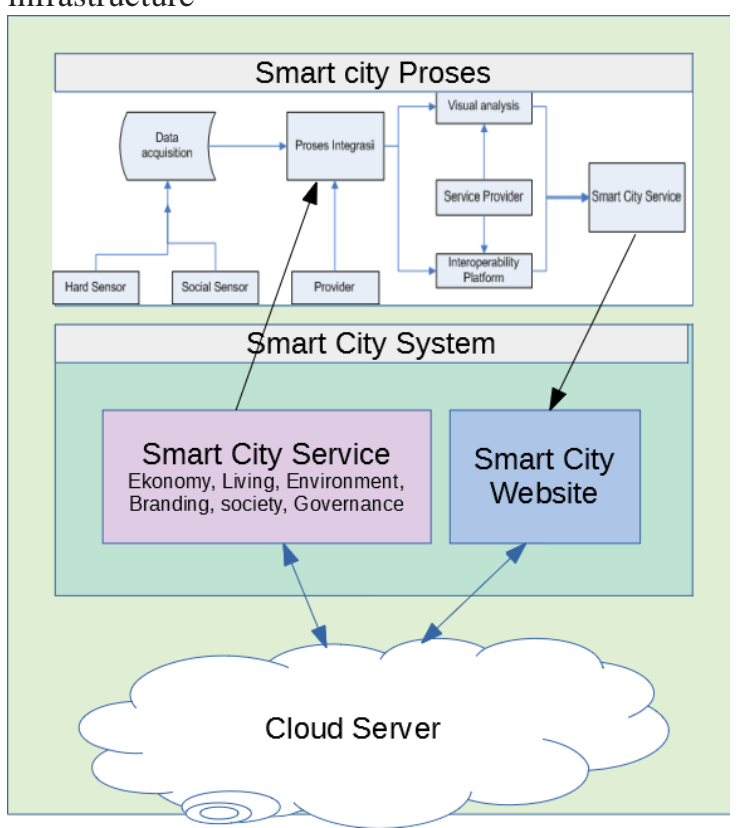

Figure 12: Enterprise Architechture

d. Migration Planning

Application of existing systems in the city of cirebon as many as 40 applications spread throughout the operation of regional devices. For migration to smart city will be taken as follows:

1. Applications that can still be used and can be integrated will be maintained and slowly updated in accordance with the needs of smart city

2. Applications that do not yet exist to support smart city will be created. 


\section{CONCLUSION}

The TOGAF enterprise architecture framework is prepared by using the right information technology, information systems, and business process needs to develop the city into a smart city because it is developed based on the analysis of the problems, challenges, needs of the townspeople and the vision of urban development in the long-term development plan of the region. The resulting information illustrates the relationship of domain technology, applications, and business processes that are easily understood by the city.

Enterprise architecture is required as a reference in selecting, planning, and developing information and telecommunication technologies to be implemented. Enterprise architecture also serves as a communication medium between stakeholders, so all stakeholders have a technology understanding to implement so that usage can improve city performance in providing services to the community.

Smart city development refers to the enterprise architecture in choosing and applying technology tends to succeed, because the enterprise architecture evolves according to the problems and challenges and needs of the city.

\section{REFERENCES}

[1] Chandra E. W. Utomo and M. Hariadi, "Strategi Pembangunan Smart City dan Tantangannya bagi Masyarakat Kota," $J$. Strateg. dan Bisnis, vol. 4, no. 2, pp. 159176, 2016.

[2] R. Yunis and K. Surendro, "Model Enterprise Architecture Untuk Perguruan Tinggi di Indonesia," Semin. Nas. Inform. 2009, vol. 2009, no. semnasIF, pp. 72-79, 2009.

[3] R. Naphade, M., Banavar, G., Harrison, C., Paraszczak, J., and Morris, "Smarter cities and their innovation challenges," Computer (Long. Beach. Calif)., vol. 6, p. 44, 2011.

[4] N. Alamsyah, T. D. Susanto, and T.-C. Chou, "A Comparison Study of Smart City in Taipei and Surabaya," A Comp. Study Smart City Taipei Surabaya, pp. 111-118, 2016.

[5] A. Samsun Hidayat, Sohono Harso Supangkat, "Designing Enterprise Architecture of Smart City," EII-Forum, 2014.

[6] J. M. Schleicher, M. Vogler, S. Dustdar, and C. Inzinger, "Application Architecture for the Internet of Cities: Blueprints for Future Smart City Applications," IEEE Internet Comput., vol. 20, no. 6, pp. 68-75, 2016.

[7] W. Purnomowati and Ismini, "Konsep Smart City Dan Pengembangan Pariwisata
Di Kota Malang," Jibeka, vol. 8, no. 1, pp. 65-71, 2014.

[8] R. E. Hall, "The vision of a Smart City," Proc. 2nd Int. Life Ext. Technol. Work., 2000.

[9] J. M. Eger, "Smart growth, smart cities, and the crisis at the pump a worldwide phenomenon," I W., vol. 32, pp. 47-53, 2009.

[10] SmartCities, "Creating Municipal ICT Architectures," Creat. Munic. ICT Arch. A Ref. Guid. from Smart Cities, 2011.

[11] Accenture, "Smart Mobile Cities : Opportunities for Mobile Operators to Deliver Intelligent Cities Acknowledgements," p. 15, 2011. 